\title{
NERVOUS DISCHARGE FROM SMALL PAINLESS LESIONS IN SKIN AND MUSCLE
}

\author{
BY \\ P. W. NATHAN \\ From the Neurological Research Unit of the Medical Research Council, \\ National Hospital, Queen Square, London
}

During an investigation of post-ischaemic paraesthesiae (Merrington and Nathan, 1949) it was noticed that during the period of ischaemia any small cutaneous lesions, such as cuts or scratches, made themselves felt, whereas they had not been noticed before. That this was no idiosyncrasy of the present author was shown by the case of a laboratory technician who had dermatitis due to formalin; he was surprised to find that shortly after the application of the cuff he felt every lesion on his fingers, although he had not previously noticed their presence. It was then considered that this phenomenon ought to be investigated at some later time. When Armstrong, Dry, Keele, and Markham (1951) published their method of producing fairly standardized blisters by cantharidin plaster, it was seen that these blisters could be used for the investigation of this phenomenon.

The purpose of this study has been to investigate the pain that may arise from a previously painless lesion when the limb is rendered ischaemic, and to relate this phenomenon to other relevant knowledge.

\section{Material and Methods}

The experiments were performed on three subjects, the author, a colleague, and the laboratory technician mentioned above, who continues to have dermatitis.

Ischaemia in the limb was induced by inflating a sphygmomanometer cuff to a pressure of $200 \mathrm{~mm}$. of mercury ; on the upper limb the cuff was placed with its lower border $2 \mathrm{~cm}$. proximal to the medial epicondyle ; on the lower limb it was placed with its lower border $3 \mathrm{~cm}$. proximal to the upper edge of the patella. Ischaemia in a short segment of nerve trunk was induced in the case of the radial nerve by means of a strap $10 \mathrm{~cm}$. wide loaded with a weight of $5 \mathrm{~kg}$., and in the case of the ulnar nerve by leaning the elbow on the table, care being taken to apply the weight of the limb to the ulnar nerve in its groove.

To produce lesions in the skin of the dorsum of the hands and fingers, it was found that it waș necessary to use double the strength of cantharidin used by Armstrong and others. Plasters containin $0.4 \%$ cantharidin were applied for eight hours br more. The superficial layers of the epideriofis raised by the blister fluid were then removed, and this left exposed a small area of the deeper layersoof the epidermis ; this exposed area will be referredto as the ulcer. The lesions due to the reaction formalin were used, and also blisters on the which happened to result from much walking if hot climate in ill-fitting shoes.

As the pain of these ulcers induced by the ischaemia is very slight, methods of increasing if were investigated. It was thought that the ulces might be made more sensitive by applying irritan $\bar{b}$ substances to it before the experiments with ischaemian were carried out so that, although the ulcer waß painless at the onset of ischaemia, it might give riset to more pain than an ulcer not so treated, during the period of ischaemia. Accordingly, various solutions, of known pain-producing agents were applied to the ulcers for some minutes before the application of the cuff ; such were potassium chloride, acetic acid, and histamine. The pain caused by these substances was only transient, lasting about two minutes. As there was no lasting effect of heightening the pain feli during ischaemia, no further report of this part of the work will be given.

Deep or muscle pain was produced by the injection of $0.2 \mathrm{ml}$. of $5 \%$ saline into the abductoro digiti minimi or the first dorsal interosseus muscle of the hand. In all experiments, and particularlyo in these on deep pain, it was found to be essentiah that the subject should not move the part at all N 
for movement alone tends to bring on pain under such circumstances.

\section{Results}

Although only one experiment of each type will be reported, in all cases two or more experiments were performed on two or three subjects.

Experiment 1.-This was the basic experiment on an artificial ulcer. A cantharidin plaster was put on the middle of the dorsum of the hand for eight hours. Ischaemia was induced 48 hours after removal of the epidermis. The area of naked dermis was $1 \mathrm{~cm}^{2}$. There is no sensation from the ulcer and no pain.

Times following application of cuff :

$1 \mathrm{~min} .30 \mathrm{sec}$. Au are of presence of ulcer from very slight pain localized to ulcer.

2 min. Tingling in hand and all digits. The ulcer is felt more clearly than the tingling.

4 min. Tingling has stopped. Ulcer continues to be felt.

$6 \mathrm{~min}$ Ulcer felt more prominently.

$13 \mathrm{~min} . \quad$ Onset of feeling of velvety numbness ; ulcer felt as before.

$15 \mathrm{~min}$ Loss of sensation of touch starting in fingers ; ulcer felt less prominently.

$18 \mathrm{~min}$. Ulcer scarcely felt.

$19 \mathrm{~min}$. Cuff off. Immediate cessation of all sensation from ulcer. No return of any sensation from the ulcer during the post-ischaemic phase. A few minutes' duration of the usual tingling and pricking.

This experiment presents the phenomenon under investigation. A painless area of exposed dermis is made very slightly painful by rendering the limb ischaemic. This definite but slight pain lasts for a longer time than the ischaemic tingling; it does not recur in the post-ischaemic phase.

Experiment 2.-The basic experiment was performed on the subject with formalin dermatitis. The lesions at this time are located on Fig. 1 as follows : $a, b$, and $c$, three small points over the first interphalangeal joint of the fourth digit ; d, a larger lesion over the metacarpophalangeal joint of the second digit ; e, a deep lesion just proximal to the first interphalangeal joint of the second digit ; $f$, scattered lesions along the radial border of the hand; $g$, little points on the ulnar side of first digit. All the lesions are on the dorsal aspect of the limb, and all consist of deep narrow cracks or pits penetrating to the dermis. Before the induction of ischaemia the subject could feel only lesion e.

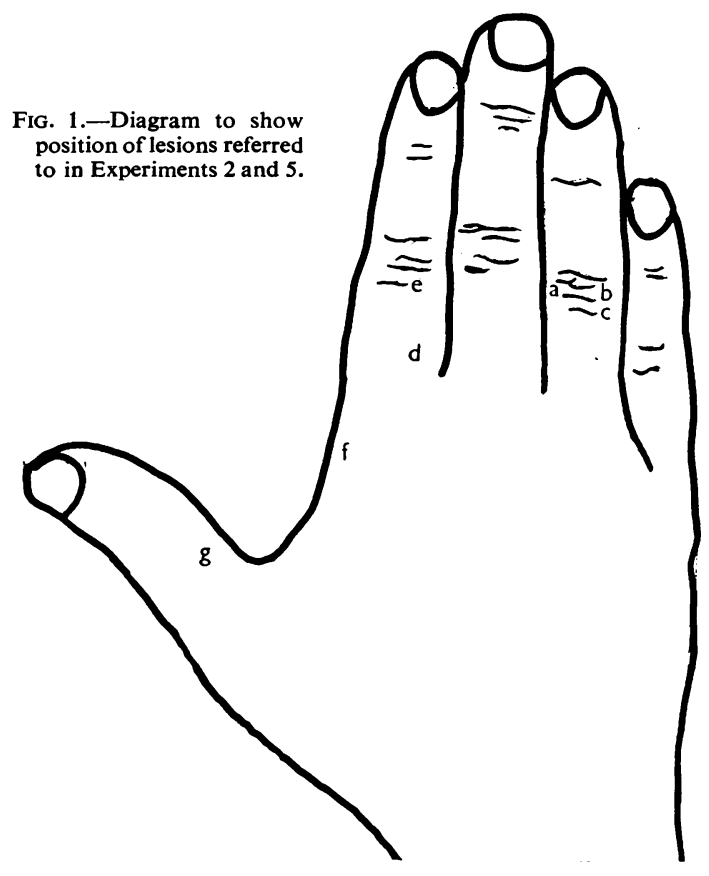

Times following application of cuff :

$1 \mathrm{~min} .15 \mathrm{sec}$. Tingling.

$3 \mathrm{~min}$. Can feel lesion e more than before.

$4 \mathrm{~min}$.

Small stabs in lesion $\mathbf{g}$.

$5 \mathrm{~min}$. Tingling has stopped. Stabbing continues in lesion $\mathrm{g}$, can feel lesion $\mathrm{f}$ : it is not painful, but it makes itself felt.

$5 \mathrm{~min} .30 \mathrm{sec}$. Lesion $\mathrm{g}$ itches, so that he has to make an effort to avoid scratching it.

$6 \mathrm{~min}$ Lesion $\mathrm{f}$ now itches equally.

$6 \mathrm{~min} .15 \mathrm{sec}$. Slight itching in lesions $\mathrm{a}, \mathrm{b}$, and $\mathrm{c}$.

$7 \mathrm{~min} .30 \mathrm{sec}$. Intense itching in lesion $\mathrm{f}$.

$8 \mathrm{~min}$

The only lesion that can now be felt is lesion $f$, and in it itching continues to be intense.

$9 \mathrm{~min}$. Lesion $f$ is now burning; therc is some burning at lesion $\mathrm{g}$.

10 min. Lesion e is now starting to hurt.

$10 \mathrm{~min} .30 \mathrm{sec}$. Lesion $\mathrm{f}$ gives a painful stinging, which is quite unpleasant.

$11 \mathrm{~min} .30 \mathrm{sec}$. Lesions $\mathrm{e}$ and $\mathrm{f}$ still felt ; no other lesions felt.

$13 \mathrm{~min}$ Very little sensation of any kind.

14 min. Cuff off.

Times following removal of cuff :

0 min. 30 sec. Irritating sharp pain in lesion $\mathrm{f}$.

$1 \mathrm{~min} .30 \mathrm{sec}$. Tingling and pricking all over hand and digits. No sensation from lesions. 
This experiment confirms the original observation, and shows that the phenomenon occurs more clearly with such naturally occurring lesions than with the induced blisters.

Experiment 3.-The basic experiment is repeated, using concentrated saline injected intramuscularly as the source of the lesion : $0.2 \mathrm{ml}$. of $5 \%$ saline is injected into the right abductor digiti minimi. Severe pain is felt for two minutes. The cuff is on one minute after pain has ceased.

Times following application of cuff :

$\begin{array}{ll}1 \mathrm{~min} . & \text { Very slight return of pain. } \\ 1 \mathrm{~min} .30 \mathrm{sec} . & \text { Pain more severe. } \\ 2 \mathrm{~min} .25 \mathrm{sec} . & \text { Pain more severe. } \\ 3 \mathrm{~min} . & \text { Tingling in periphery of limb. } \\ 3 \mathrm{~min} .20 \mathrm{sec} . & \begin{array}{l}\text { Pain less. } \\ 3 \mathrm{~min} .30 \mathrm{sec} .\end{array} \\ & \begin{array}{c}\text { Tingling more marked in ulnar } \\ \text { distribution. }\end{array} \\ 5 \mathrm{~min} .05 \mathrm{sec} . & \text { Tingling gone. } \\ 8 \mathrm{~min} .15 \mathrm{sec} . & \text { Pain has increased slightly. } \\ 9 \mathrm{~min} . & \text { Pain slightly more severe. } \\ 13 \mathrm{~min} .15 \mathrm{sec} . & \text { Pain less. } \\ 15 \mathrm{~min} . & \text { Pain just present. Cuff off. }\end{array}$

Times following removal of cuff :

0 min. $15 \mathrm{sec}$. Pleasant warmth, pain gone.

This experiment shows that the phenomenon occurs for deep or muscle pain as for skin or superficial pain.

In all experiments the induced pain passes off a long time before ischaemia causes any analgesia.

Experiment 4.- Nerve ischaemia was induced by strapping. The plaster was on the skin supplied by the radial nerve for $10 \frac{1}{2}$ hours. Ischaemia was induced four days after the removal of epidermis.

Strapping was placed over the arm so as to compress the radial nerve; the length of nerve compressed was about $10 \mathrm{~cm}$. The area of naked dermis was $0.4 \mathrm{~cm}$. diameter.

Times following application of strapping :

\begin{tabular}{|c|c|}
\hline $2 \mathrm{~min}$. & Tingling in radial skin area. \\
\hline $4 \mathrm{~min}$. & Tingling more intense. \\
\hline $8 \mathrm{~min}$. & Nothing felt. \\
\hline $14 \mathrm{~min}$. & Very slight smarting in ulcer. \\
\hline $16 \mathrm{~min}$ & Smarting now quite definite. \\
\hline $21 \mathrm{~min} .30 \mathrm{sec}$. & Nothing felt now. \\
\hline $24 \mathrm{~min}$ & $\begin{array}{l}\text { Onset of loss of touch sensation. } \\
\text { Strapping removed. Nothing felt in } \\
\text { post-ischaemic phase. }\end{array}$ \\
\hline
\end{tabular}

In this experiment there was no interference with the blood supply or venous drainage of the ulcer or of the free nerve-ending in the lesion. Thus rendering $10 \mathrm{~cm}$. of the relevant nerve ischaemic causes the phenomenon. It can be concluded that the pain is not caused by rendering the nerve endings anoxic nor by increasing the tension in the tissues of the lesion nor by damming up any chemical substances in the lesion, but that it is caused by rendering ischaemic the nerve supplying the lesion.

Experiment 5.-The previous experiment was repeated on the subject with dermatitis. It was considered that if only those lesions within the territory of the radial nerve were made irritating or painful and not the other lesions this would be adequate confirmation of the previous experiment. The lesions are labelled as before, but some change in the lesions has taken place since the previous experiment on this subject. Lesion c now consists of a crack over the first interphalangeal joint of the fourth digit. Lesion d consists of multiple punctate lesions over the metacarpo-phalangeal joint of the second digit. Lesion e is just proximal to the first interphalangeal joint of the second digit, and measures $1 \mathrm{~cm}$. mediolaterally. Lesion $\mathrm{g}$ consists of multiple punctate lesions on the ulnar side of the base of the first digit; it is covered with scabs, and no dermis is exposed. Lesion $f$ has now healed, and no longer exists.

Strapping and a $5 \mathrm{~kg}$. weight were applied so as to compress the radial nerve.

Times following application of strap :

0 min. $15 \mathrm{sec}$. Tingling on dorsum of first and second digits and dorsum of hand in radial distribution.

$0 \mathrm{~min} .50 \mathrm{sec}$. Tingling less.

$6 \mathrm{~min}$. Very slight tingling in median distribution. (This nerve was doubtless also compressed by the weight of the arm and the $5 \mathrm{~kg}$.)

7 min. All tingling gone.

$8 \mathrm{~min}$. Nothing felt.

$11 \mathrm{~min}$. Aware of lesion e. $\mathrm{He}$ had not previously been aware that he had a lesion here.

12 min. Aware of lesion d.

$13 \mathrm{~min}$. Lesions $\mathrm{d}$ and e more obvious.

$14 \mathrm{~min}$. Lesion e no longer felt. More pain in lesion d.

17 min. All pain gone. Other lesions were not felt throughout.

It will be noted that in this experiment lesion c, which was a deep one, was not felt. Nor was lesion $\mathrm{g}$, but as it was covered with scabs, it is unlikely that there were any free nerve endings to be irritated. This experiment confirms Experiment 4; it is the more striking as the subject has no knowledge of 
anatomy and could not know which lesions lay within the distribution of the ulnar nerve and which within that of the radial.

Experiment 6.-Ischaemia was induced by pressure on the nerve. Concentrated saline injected intramuscularly was used as the source of the lesion; $0.2 \mathrm{ml}$. of $5 \%$ saline was injected into the first dorsal interosseous muscle of the upper limb. This caused intense pain for two minutes. Two minutes after the pain had gone pressure was applied to $2 \mathrm{~cm}$. of the ulnar nerve in its groove.

0 min. $30 \mathrm{sec}$. A few seconds of tingling in the distribution of the ulnar nerve.

$1 \mathrm{~min}$. Tingling is now continuous.

2 min. Slight burning pain in the muscle at the site of the injection.

$5 \mathrm{~min}$. Pain has gone.

9 min. Tingling has gone.

$15 \mathrm{~min}$.

Velvety numbness in skin area supplied by ulnar nerve. Pressure removed.

This experiment shows that ischaemia applied to a short segment of nerve induces deep pain as well as superficial pain in lesions previously painless.

It has so far been shown that pain can be induced in a small somatic lesion when only a short segment of the nerve supplying the lesion is rendered ischaemic; to cause this phenomenon it is unnecessary to alter the blood supply of the lesion itself. The next question to be answered is whether the nerves supplying the lesion have in some way been made sensitive, so that they alone are susceptible to ischaemia, or whether functioning nerveendings in the lesion are necessary to cause the phenomenon. The following two experiments were performed to attempt to answer this question.

Experiment 7.-This took the form of the basic experiment with obliteration of nerve-endings in an ulcer, and was performed on a six-day-old ulcer on the left hand. Pain came on after 24 seconds, and lasted for nine minutes. After this experiment the ulcer was covered with $2 \mathrm{~N}$ hydrochloric acid. This effectively coagulated all the protein of the lesion, penetrating deep enough to cause a permanent - scar. Twenty-four hours later this lesion was totally anaesthetic to all forms of stimulation, and free from any sensation when it was rubbed; it was covered with a smooth, yellowish, translucent scab. A control ulcer had been made on the other hand at the same time and of the same size as that on the left hand; but the control ulcer was not coagulated. Cuffs were now placed on both arms and inflated. On the right control hand pain was felt in the ulcer after four minutes, and it lasted for eight minutes. On the left limb, although the cuff was inflated for 30 minutes, no pain was felt, and there was no awareness of any kind of sensation from the ulcer.

The standard experiment carried out on the right limb before the coagulation of the ulcer and that carried out on the left limb serve as controls to show that the nerves in the ulcer would have been capable of discharging had they not been coagulated. This experiment shows that for pain to be induced by ischaemia applied to the nerve, free nerve-endings must be functioning in the lesion; and conversely, it shows that when the nerve-endings have been functionally cut off from the nerve above them, pain cannot be produced in the lesion by the application of ischaemia to the nerve supplying it. This is shown diagrammatically in Fig. 2.

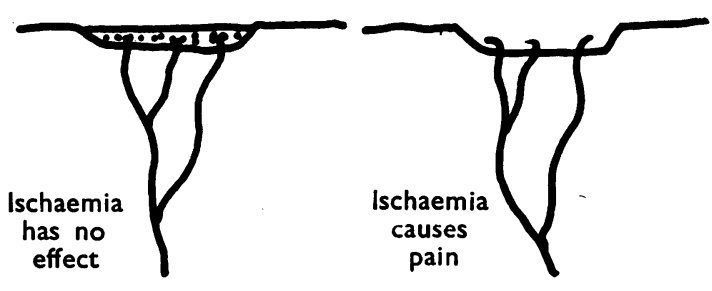

FIG. 2.-Nerve-endings in coagulated and normal ulcer.

It may be concluded, that although the ischaemic pain can be induced by rendering a proximal segment of the nerve ischaemic, it can do so only when there is a nervous discharge from free nerveendings within the lesion.

This condition is confirmed by the next experiment. Here the free nerve-endings within the lesion are left intact, but a block is placed on the nerve between the lesion and the cuff.

Experiment 8.-This consisted of the basic experiment with a procaine block on the nerve between the lesion and the cuff. Ischaemia was induced 24 hours after the removal of the superficial layer of the epidermis from a cantharidin blister. The area of the ulcer was $1 \times 1.25 \mathrm{~cm}$.

Two per cent. procaine hydrochloride, $2 \mathrm{ml}$, was injected into the skin, just proximal to the ulcer, as shown in Fig. 3.

One minute after the injection of the anaesthetic solution acetic acid was placed on the ulcer to test its sensitivity ; it was felt minimally. Three minutes later, when acid was put on it again, nothing was felt. The cuff was then placed on the arm and inflated for 15 minutes. No sensation from the ulcer was experienced. 


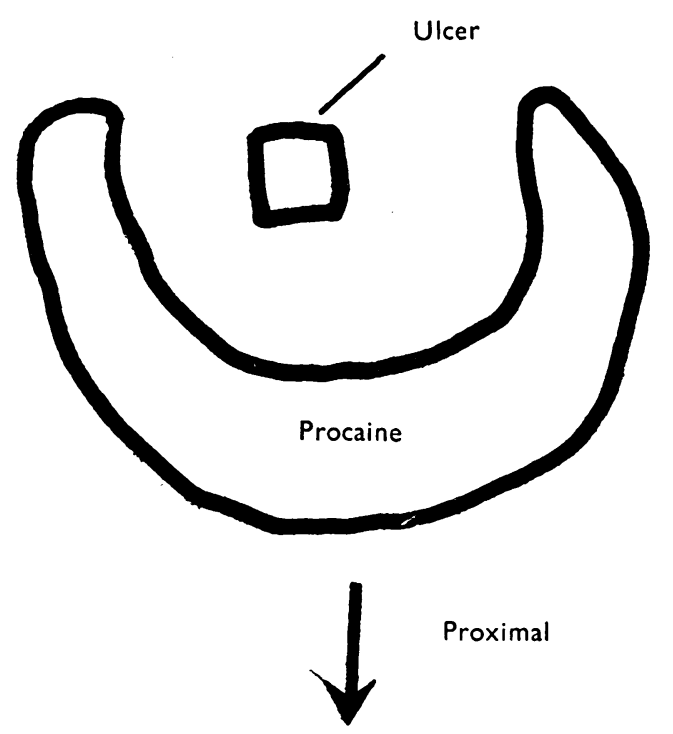

FIG. 3.-Diagram showing site of procaine injection proximal to ulcer.

Four hours later the effect of the local anaesthetic block had worn off, and stimulation of the ulcer caused pain. The cuff was re-applied. After two and a half minutes the ulcer was distinctly felt, and continued to be obvious for 10 minutes.

This experiment, by another method, confirms the conclusions drawn from Experiment 7. Although ischaemia induced in a segment of nerve a long way proximal to a lesion causes pain, it does so only when free nerve-endings are functioning at the site of the lesion.

Experiment 9.-The effect of alkalaemia was studied. As some of the changes in function which occur when a nerve is subjected to ischaemia also occur when the nerve is subjected to alkalaemia, it was of interest to find out if over-breathing also makes the painless lesions painful. The cantharidin plaster was applied for 18 hours. Overbreathing was performed half an hour after the superficial layers of the epidermis had been removed.

The area of the ulcer was $0.5 \times 0.25 \mathrm{~cm}$. Overbreathing was continued for 100 seconds. After 60 seconds tingling in the tips of the fingers was felt. Before the 100 seconds were past, the ulcer, which is proximal to the metacarpo-phalangeal joint and thus proximal to the area of tingling, became definitely but very slightly painful.

It may be concluded from this experiment that alkalaemia as well as ischaemia can make the lesion painful.
Experiment 10 (a) and (b).- - These were designed to study the effect of combined ischaemia and alkalaemia. The lesion consisted of an ulcer on the dorsum of the right foot situated between the first and second digits over their metacarpo-phalangeal joints. The ulcer was $0.75 \times 0.75 \mathrm{~cm}$.; it had a purulent base, and was surrounded by 1 to $2 \mathrm{~cm}$. of oedematous tissue.

10(a). Effect of Ischaemia Alone.-Before the cuff was applied the ulcer could be slightly felt.

Times following application of cuff :

$4 \mathrm{~min} .50 \mathrm{sec}$. Slight aching in ulcer margin.

$5 \mathrm{~min} .40 \mathrm{sec}$. More severe.

$12 \mathrm{~min}$.

Pain still present. Cuff released.

0 min. $15 \mathrm{sec}$. After release of cuff : Slight feeling of tension in ulcer for about 5 secs. Then nothing.

10(b). Effects of Alkalaemia and Ischaemia Combined.-The same ulcer as before, which by now was painless unless attention was directed towards it; then it could be appreciated that it ached slightly.

One minute overbreathing :

After 20 sec. L.ight-headed.

After 45 sec. Dizziness.

After 60 sec. Cuff inflated and overbreathing stopped.

Times following application of cuff :

$3 \mathrm{~min} .20 \mathrm{sec}$. Onset of pain in ulcer.

$3 \mathrm{~min} .35 \mathrm{sec}$. Pain increasing.

$4 \mathrm{~min}$.

Pain obvious and constant.

$4 \mathrm{~min} .30 \mathrm{sec}$. Whole oedematous area feels sore.

$6 \mathrm{~min} .10 \mathrm{sec}$. Quite a lot of pain.

$6 \mathrm{~min} .30 \mathrm{sec}$. This pain would now be intolerable were it to continue for hours. It is too severe to permit reading. The whole of the first digit aches, and the ulcer itself seems to be the centre of the area of aching pain.

$12 \mathrm{~min}$ Pain as before. Cuff off. Immediate feeling of heat. Lesion still felt slightly but the sensation is pleasant and warm.

$0 \mathrm{~min} .30 \mathrm{sec}$. After release of cuff: Lesion no longer felt.

This experiment shows that the combined effect of alkalaemia and ischaemia makes the pain more marked than when it is caused by either alone.

Experiment 11.-The effects of alkalaemia on a lesion due to intramuscular concentrated saline were studied. Five per cent. saline, $0.2 \mathrm{ml}$., was injected into the abductor digiti minimi. Pain started immediately and lasted for 4 minutes 50 
seconds. Overbreathing was practised for two minutes.

After $1 \mathrm{~min}$. Lightheaded.

After $1 \mathrm{~min} .45$

sec. Jerks in both upper limbs.

After $2 \mathrm{~min}$. Cuff applied. By this time, consciousness was disturbed, and it had been so for at least 15 seconds. The subject was quite unaware that his limbs were jerking, did not know that the cuff had been applied, continuously asking for it to be put on, and he would not or could not stop overbreathing, although he was repeatedly told to stop. No pain or tingling was felt during this two minutes, but the subject was unable to observe during the latter period.

Times following application of cuff :

$1 \mathrm{~min} .50 \mathrm{sec}$. Slight aching in the region of the injection.

$2 \mathrm{~min} .40 \mathrm{sec}$. Tingling in periphery of limb, more marked in region of injection.

$3 \mathrm{~min} .30 \mathrm{sec}$. Tingling gone, aching still present.

$4 \mathrm{~min}$. Pain increasing, felt only in muscle.

$6 \mathrm{~min} .30 \mathrm{sec}$. Pain increasing.

$11 \mathrm{~min}$. Pain decreasing.

$12 \mathrm{~min}$. Pain almost gone.

$13 \mathrm{~min}$. Cuff off.

Times after removal of cuff :

$0 \mathrm{~min} .30 \mathrm{sec}$. Tingling in periphery of limb; lesion just felt.

$1 \mathrm{~min}$. Pricking in periphery of limb ; lesion still just felt.

4 min. 15 sec. Pricking gone; tingling continues; lesion still just felt.

5 min. Tingling just present; lesion no longer felt.

This experiment shows that for deep pain as for skin pain the combined effect of ischaemia and alkalaemia induces more pain than either alone.

\section{Conclusions}

The observation that when a limb is rendered ischaemic lesions in the skin or muscle which were not felt may become felt and/or painful suggests the following questions : (1) Does the ischaemia cause the phenomenon under consideration by making the free nerve-endings in the lesion discharge, whereas they had not been doing so before the ischaemia, or (2) does it act by " magnifying" the discharge which was already present, but very slight and not appreciated as pain ? (3) If ischaemia acts by increasing the irritability of the nerveendings or nerve fibres do other factors known to increase this irritability also cause the phenomenon?

It was shown by Thörner (1924) that the first effect of anoxia on frog's nerves is to cause an increase in excitability, as shown by the strength of current necessary to stimulate the motor nerve. This change occurs within five minutes of the onset of the anoxia, and reaches a maximum in 10 to 30 minutes. Heinbecker (1929) also studied the effect of anoxia on those peripheral nerves of the frog which give rise to the alpha, beta, gamma, and delta potentials of the A group. He did not study the $\mathrm{C}$ fibres, although it is likely that some of the fibres which he studied, in particular those of the delta group, subserve the modality of pain. He also found that for the first 15 to 30 minutes of anoxia the threshold is lowered, the action potential is usually increased in amplitude, and the conduction rate is increased. Thompson and Kimball (1936), who also induced ischaemia in man by means of a sphygmomanometer cuff, investigated the irritability of the median, radial, and ulnar nerves by stimulating them through the skin at the wrist; they found that the voltage necessary to stimulate these nerves reached a minimum after 10 minutes of ischaemia, and that it rose abruptly after 15 minutes of ischaemia. Kugelberg (1944) showed that ischaemia and the alkalaemia caused by overbreathing bring about a lowering of accommodation and an increased excitability in the peripheral nerves ; the lowering of the rheobase occurs within a few seconds of the application of the cuff. All types of nerve fibres do not show this change with the same amount of ischaemia. Kugelberg (1946) found, for example, that " normally, activity in motor fibres is obtained merely in isolated cases during ischaemia, and afterwards only if the pneumatic cuff has been kept on for about half an hour. The investigation of motor impulses, however, can be facilitated by reducing the amount of ionized calcium in the blood, e.g. by hyper-ventilation ". He showed that essentially the thick motor fibres behave in the same way as the large sensory fibres, spontaneous activity occurring when their excitability exceeds a certain critical value.

Thus, the effect of ischaemia applied to nerves, as reported in this previous work, is to cause an increased excitability or irritability of the nerve rendered anoxic. It is probable that the ischaemia affects all types of nerve fibres in this way.

The phenomenon investigated in the present work, however, differs in one main respect from the work mentioned above. It was shown by Merrington and Nathan that the nervous discharge investigated by Kugelberg arises in the segment of nerve rendered ischaemic ; the paraesthesiae, which are the sensations accompanying the breakdown in accommodation of the nerve fibres, occur where there are no nerve-endings present, as in cases of amputation or 
complete lesions of peripheral nerves; they also occur when the nerve distal to the cuff is blocked for conduction by local anaesthetic. Thus the kind of nervous discharge previously studied arises entirely in the part of the nerve rendered ischaemic. In the kind of nervous discharge investigated in the present study, free nerve-endings in the lesion giving rise to impulses are needed before ischaemia applied to a proximal segment of nerve can cause the sensation. Further, the fact that a block placed on the nerve between these end-organs and the segment of nerve rendered ischaemic stopped the phenomenon shows that such free nerve-endings must be discharging for the phenomenon to occur. Thus the main difference between the phenomena previously investigated by Kugelberg and by Merrington and Nathan, and that investigated here, is that in the previous phenomenon the impulses arose solely in the ischaemic segment of nerve, whereas in the present phenomenon participation of impulses arising in the periphery is necessary. It would seem that when the impulses arise solely in the nerve, paraesthesiae are felt, and when the impulses arise in the proper receptor, a normal sensation is felt.

It seems that one may conclude from this work that impulses from painless lesions may be constantly passing into the central nervous system, although under normal circumstances they are insufficient to be perceived.

It is perhaps surprising that no pain was felt during the post-ischaemic phase. For it is during this phase that the nerves are rendered most excitable. This might be accounted for by the small extent of the lesions; any slight pain from them might perhaps not be felt among the mass of pricking and tingling felt in the periphery of the limb. It might perhaps be accounted for by the different effect of the same duration of ischaemia on nerve fibres of different sizes. Far longer periods of ischaemia are needed to cause pseudo-cramp, for instance, than tingling ; it could be that still longer periods of ischaemia are needed to cause postischaemic pain.

It was stated above that the lesions became more prominent in consciousness, or that they became slightly painful, or that-in one case-they started itching. It seems that one may conclude that the nerves discharging are those subserving the modality of pain. This conclusion is based not only on the nature of the sensation evoked by ischaemia, but also on the fact that the sensations are not paraesthesiae-for they require the discharge of impulses from the lesion itself-and also on the fact that the sensations are felt in the lesions of the skin and muscle, and pain is the specific modality of lesions. Hence it is believed that these slight sensations are weak, or if one may express it so, subliminal, pain. In support of this hypothes's, the work of Bishop (1944) may be referred to. He showed that stimuli which, when summated caused " frank pain ", caused, before they were adequate to give rise to pain, a pulsating sensation, "inconsequential touch ", or itch.

Two ideas which may have some general importance emerge from this study. The one is that somatic lesions which are not felt may nevertheless be discharging impulses into the central nervous system, and that such impulses could have effects. This might be expressed by saying that there is such a thing as subliminal pain. The other idea is that the discharge from such lesions may be increased so that an actual sensation is experienced, by means of everyday occurrences such as ischaemia or alkalaemia.

Lewis (1942) observed that arresting the blood flow to the hand with a recent blister or to "skin rendered hyperalgesic by crisscross scratching or by ultraviolet light " causes pain when no spontaneous pain is present before the arrest of the circulation. $\mathrm{He}$ argued that this pain is due to the accumulation in the damaged skin of "some pain-giving substance", and that the relief of pain in the postischaemic phase is due to the washing away of this accumulated substance. It may now be suggested that Lewis's explanations fit the observed facts less well than the concepts put forward here : that the pain occurring during ischaemia is due to the irritating effect of ischaemia on the nerve supplying the lesion, and this effect increases the minimal impulses from the free nerve-endings, which had previously been insufficient to arouse a conscious sensation.

It has been observed by Addis, Jepson, and Kellgren (1950) that arterial occlusion increases the pain of deep suppuration, operation wounds, and some cases of superficial suppuration. It may be suggested that this increased pain is also due to an increase in the excitability of the nerve fibres supplying the lesion induced by ischaemia, as described in this study.

\section{Summary}

It was found that small painless somatic lesions could be rendered painful by making the limb ischaemic. An investigation of this phenomenon showed that ischaemia caused this effect when it was applied to only a short length of the nerve supplying the lesion. The lesions could be made painful also by alkalaemia. The phenomenon and its implications are discussed. 
I would like to thank Dr. John Marshall not only for being the subject for the experiments, but also for his stimulating discussions, and I would also like to thank Dr. E. Arnold Carmichael for his interest and constructive criticism.

\section{REFERENCES}

Addis, H. St. C. C., Jepson, R. P., and Kellgren, J. H. (1950). Clin. Sci., 9, 271.
Armstrong, D., Dry, R. M. L., Keele, C. A., and Markham, J. W. (1951). J. Physiol., Lond., 115, 59 P.

Bishop, G. H. (1944). J. Neurophysiol., 7, 71.

Heinbecker, P. (1929). Amer. J. Physiol., 89, 58.

Kugelberg, E. (1944). Acta

$\longrightarrow$ (1946) Brain, 69, 310 . Macmillan, New York.

Lewis, T. (1942). Pain. Macmillan, New York.

Merrington, W. R., and Nathan, P. W. (1949). Neurosurgery and Psychiatry, 12, 1.

Thompson, I. M., and Kimball, H. S. (1936). Proc. Soc. exp. Biol., N.Y., 34, 601.

Thörner, W. (1924). Pfiügers Arch ges. Physiol., 204, 747.

\section{Foundations' Fund for Research in Psychiatry}

The Social Research Foundation has made a grant of approximately six million dollars for psychiatric research to Yale University and requested the Corporation of Yale University to establish the Foundations' Fund for Research in Psychiatry. The purpose of this new foundation is, in the words of the donor, " to support research into why people become mentally and emotionally ill, why they get well, how best to help them get well and how best to help them from becoming mentally and emotionally ill."'

The distribution of this fund will not be confined to Yale University. Present plans contemplate that both income and principal will be expended in accordance with the stated purpose over a period of about 20 years.
At its initial meeting held in New Haven on March 27 and 28, the Board of Directors discussed organization and general policy questions. It expressed interest in the training and support of competent investigators, in the development of appropriate research methods, in encouraging the pursuit of significant problems, and in the advancement of the basic behavioral and biological sciences as related to psychiatry.

The Board invites the communication of ideas from interested sources but will not be ready to make decisions on grants for at least six months (from April, 1953).

The temporary address of the new organization is 333 Cedar Street, New Haven 11, Connecticut, U.S.A.

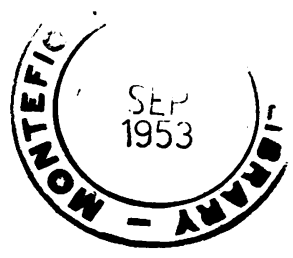

